\title{
Entre o singular e o coletivo: a experiência de um serviço na abordagem das anorexias e bulimias
}

I 1 Alexandre Costa Val, 2 Maria Bernadete de Carvalho,

${ }^{3}$ Rosana Onocko Campos I

Resumo: Investiga-se o manejo das dimensões do coletivo e do singular no âmbito de serviços de saúde orientados, ou, senão, tensionados pela psicanálise. A discussão teórica é sustentada pela descrição de um serviço público voltado para a atenção a sujeitos com diagnóstico de bulimia e/ou anorexia, cuja orientação clínica é dada pela construção dos casos, em equipe interdisciplinar. Os dados foram obtidos através de consultas a documentos do serviço e por meio da observação e participação direta em suas atividades clínicas. Evidencia-se o privilégio dado nesse serviço à singularidade na clínica como forma de tratamento das particularidades do coletivo em questão.

Palavras-chave: anorexia; bulimia; psicanálise; Saúde Coletiva.
1 Fiocruz (René Rachou), Saúde Coletiva. Belo Horizonte-MG, Brasil. Endereço eletrônico: alecostaval@yahoo.com.br

2 Faculdade de Medicina, Universidade Federal de Minas Gerais, Medicina Preventiva e Social. Belo Horizonte-MG, Brasil. Endereço eletrônico: bernadetec59@gmail.com

${ }^{3}$ Faculdade de Ciências Médicas, Universidade Estadual de Campinas. Campinas-SP, Brasil. Endereço eletrônico: rosanaoc@mpc.com.br

Recebido em: 10/03/2014 Aprovado em: 02/12/2014 
A Saúde Coletiva, ao ser entendida como um núcleo ${ }^{1}$ interdisciplinar por excelência, envolve metodologias, técnicas e saberes diversos, esforçando-se por apreender conceitualmente e desenvolver formas de abordagem à altura da complexidade de seu objeto: o processo de saúde-doença e a intervenção em sua dimensão coletiva. Originária de um movimento dos profissionais da saúde pública e da medicina preventiva e social nos anos 1980, a Saúde Coletiva assume uma crítica ao positivismo do modelo biomédico, privilegiando o social como categoria analítica (CAMPOS, 2000).

No Brasil, as contribuições das ciências sociais para esse núcleo sofreram um deslocamento de ênfase que se fez sensível nos anos 1990, quando estudos de cunho estruturalista, sobretudo os de orientação marxista, cederam lugar aos estudos de bases empírico-sociológica ou fenomenológica. Trata-se de trabalhos interpretativos, etnográficos e de representaçōes que reivindicam a dignidade das questôes dos sujeitos, em contraste com seu abandono nas análises de orientação estruturalista. No entanto, esse deslocamento se limitou à abordagem do sujeito racional, seja ele histórico, social e/ou coletivo, e poucos consideraram o sujeito do inconsciente e a economia pulsional (ONOCKO-CAMPOS, 2012).

É importante precisarmos o sujeito a que nos referimos quando o associamos ao termo "inconsciente" para entendermos as consequências disso para Saúde Coletiva. Antes de mais nada, é preciso destacar que o sujeito do inconsciente difere drasticamente do indivíduo ou do sujeito racional cartesiano. Lacan (1957) subverte o cogito de Descartes, "penso, logo existo", propondo "penso onde não sou, sou onde não penso". Assim, ele adverte que o sujeito está presente justamente no lugar em que ele não pensa, esclarecendo que o sujeito não é o que resulta de uma elaboração de saber, que ele não se reduz à subjetividade, ou seja, ele não se reduz a tudo o que se pode pensar e que engloba a consciência de si, do mundo e da relação entre ambos. Lacan situa o sujeito da psicanálise em um intervalo, entre um significante e outro. Dito de outra forma, ele o situa na divisão entre o significante que o nomeia e o que lhe escapa, apontando, assim, para o espaço de atuação das pulsões, que buscam satisfação e que devem ser levadas em consideração na análise das escolhas humanas (LACAN, 2008).

Outro ponto que merece destaque é a aparente disjunção entre inconsciente e responsabilidade. É comum que se depreenda da obra freudiana a ideia de que o 
inconsciente é constituído por traços traumáticos de uma história passada que se inscreveram na memória. Essa interpretação tende a aproximar a metapsicologia freudiana do empirismo científico, sustentando uma visão determinista do sujeito. Ou seja, o sujeito deixa de ser responsável por suas ações, uma vez que é determinado por algo que já está inscrito em seu inconsciente, assim como ocorre quando se busca explicar os acontecimentos da vida a partir de pressupostos biológicos cientificamente conhecidos. Lacan, ao reler Freud, ressalta que a história do sujeito é uma reinscrição que se reatualiza no presente, e não uma mera determinação da memória de um passado (FORBES, 2012). O inconsciente freudiano é inconsistente, fugidio e jamais poderá ser apreendido por completo. É essa concepção que Freud (1937) destaca em seu texto Análise terminável e interminável, ao afirmar que é impossível que o analisante se livre por completo de uma exigência pulsional, ficando sempre um resto no final de uma análise. Trata-se de algo indizível que convoca o sujeito a um posicionamento. Para Lacan, a psicanálise visa a responsabilidade com relação a esse ponto de não saber.

Entender o sujeito do inconsciente como aquele que escapa à razão, sendo, ainda assim, responsável por suas ações, pode trazer importantes consequências no campo da saúde. Assumir que os atores da saúde, sejam eles profissionais ou pacientes, são sujeitos do inconsciente que buscam satisfações pulsionais pode mudar a gestão das equipes de saúde e as relações destas com os pacientes (ONOCKOCAMPOS, 2012). Talvez isso possibilite o advento daquele paciente que é "sujeito de sua própria saúde”, como desejam muitos dos profissionais da saúde hoje. Com a psicanálise, sabe-se, no entanto, que essa responsabilidade nem sempre se constrói em consonância com as exigências de adaptação a padróes ideais. A escuta da singularidade permite localizar as invençōes dos sujeitos para lidar com o que é impossível de subjetivar, de forma a se fazerem incluir no vínculo social.

Onocko-Campos (2012), ao defender a relevância das contribuições dos conceitos psicanalíticos para os campos teórico e prático da Saúde Coletiva, questiona o senso comum de que a psicanálise seja uma atividade que pressupõe um trabalho restrito aos consultórios particulares destinados às classes mais favorecidas, enquanto a Saúde Coletiva seria uma atividade que pressupõe intervenções no exterior, na sociedade, no que é coletivo. Afinal, não há "um sujeito do inconsciente possível de se desenvolver em uma cápsula hermeticamente isolada do seu meio cultural e social” (p. 13). 
As mutações históricas dos sintomas, assim como a frequência destes, foram temas que interessaram a Freud em diversos momentos de sua obra. Ele já se colocava inclusive a questão de saber quais adaptaçōes nas técnicas da psicanálise seriam necessárias, quando fosse reconhecida a nocividade das neuroses em saúde pública (FREUD, 1919 [1918], p. 180):

[...] um dia a consciência da sociedade despertará, e lembrar-se-á de que o pobre tem, exatamente, tanto direito a uma assistência $\grave{a}$ sua mente, quanto o tem agora a ajuda oferecida pela cirurgia, pois as neuroses ameaçam tanto a saúde pública quanto a tuberculose, e, como esta, também não podem ser deixadas aos cuidados impotentes de membros individuais da comunidade. [...] Defrontar-nos-emos, então, com a tarefa de adaptar a nossa técnica às novas condiçôes.

Diferentemente do que muitos pensam, a psicanálise reinventa-se e está mais viva do que nunca, constituindo-se como importante presença nos movimentos sociais que surgem em resposta aos novos processos de saúde-doença do mundo contemporâneo. Ela orienta o trabalho em saúde mental de alguns serviços e de muitos dos profissionais que atuam na rede pública de saúde, em instituiçôes judiciárias, ONGs, programas e serviços governamentais destinados a infratores, junto a associações civis, para citar algumas das experiências atuais. Nelas, coabitam o coletivo e o singular, o que permite soluções inéditas, reintroduzindo, por vezes, a possibilidade do vínculo social, seja ele com a família, com as instituições, com o cuidador, com o trabalho, etc.

Se essas experiências não cessam de se produzir, parece não haver, no entanto, uma fórmula capaz de reproduzir de forma previsível o retorno de um sujeito ao laço social. Da mesma forma, o ato analítico, que visa facilitar esse laço, não se mostra programável. Nenhum setting garante o ato analítico, nem sua ausência o impede. É o que Miller (2009) propõe ao desenvolver a ideia do "lugar alfa" que a psicanálise pode ocupar nas instituições. Ele afirma que os efeitos psicanalíticos não dependem do terreno apropriado dos consultórios nem da natureza de sua clientela, mas sim do engajamento do analista em sua experiência de formação. Uma formação adequada permite ao praticante suportar um laço favorável ao ato análitico e se tornar um objeto nômade, passível de transitar por diversos contextos. $\mathrm{O}$ analista, ao se posicionar no lugar dito alfa, possibilita que a fala do sujeito acolhido retorne de forma invertida como um saber inconsciente de que ele próprio ignorava ser a sede. Abre-se, então, a possibilidade de que o sujeito 
reafirme ou refaça suas escolhas, e se libere para uma satisfação no vínculo social.

$\mathrm{O}$ analista, ao ocupar esse lugar, explicita uma conexão direta com o social e os efeitos de suas manobras evidenciam, finalmente, que a realidade psíquica é a realidade social de cada $\mathrm{um}$.

Nossa pergunta incide, justamente, sobre a convivência entre a perspectiva da Psicanálise e a da Saúde Coletiva que se verifica nas diversas experiências acima citadas. Neste artigo, a investigação sobre o modo como ocorre essa convivência entre o singular e o coletivo, no âmbito de serviços de saúde orientados ou, senão, tensionados pela psicanálise, será realizada a partir do exame de uma dessas experiências.

Trata-se do ambulatório mantido pelo Núcleo de Investigação em Anorexia e Bulimia (NIAB), um serviço vinculado ao Hospital das Clínicas da UFMG e inscrito como atividade de extensão universitária. $\mathrm{O}$ ambulatório oferece atenção de caráter interdisciplinar a sujeitos com diagnóstico de anorexia e/ou bulimia nervosas, contribuindo também para a formação de profissionais interessados. Sua orientação clínica pauta-se pela construção psicanalítica dos casos.

Os dados que embasam a descrição do serviço foram obtidos através de consultas a documentos do serviço, mas, sobretudo, por meio da observação e participação direta dos pesquisadores nas atividades do NIAB. ${ }^{2}$ De forma preliminar, convém, no entanto, abordar a questão de saber se podemos inscrever os diagnósticos de anorexia e bulimia nervosas no rol dos problemas de saúde pública, no contexto brasileiro contemporâneo.

\section{Anorexias e bulimias: problemas de saúde pública?}

Os transtornos alimentares são descritos no Manual de Diagnóstico $e$ Estatística dos Transtornos Mentais IV Revisado (DSM IV-R) ${ }^{3}$ como síndromes psiquiátricas caracterizadas por severas perturbações no comportamento alimentar, habitualmente motivadas por uma distorção da imagem corporal. As classificações incluem anorexia nervosa, bulimia nervosa e transtorno alimentar sem outra especificação (APA, 2002).

A baixa prevalência de transtornos alimentares na população geral, a variabilidade dos critérios adotados para o diagnóstico e algumas características como a vergonha, a omissão ou mesmo a falta de conhecimento sobre o assunto fazem com que os estudos epidemiológicos nesse campo sejam especialmente 
complicados (NUNES, 2006). As pesquisas existentes, no entanto, indicam uma prevalência de 0,3 a $0,9 \%$ de anorexia nas adolescentes e mulheres jovens ocidentais. A prevalência desse transtorno em mulheres, durante a vida, varia de $1,2 \%$ a $2,2 \%$. Já a bulimia é mais frequente que a anorexia, com prevalência estimada entre $1 \%$ a $2 \%$ entre as mulheres jovens. Alguns autores sugerem que essas taxas estejam subestimadas, destacando que elas são bem mais altas quando se consideram as síndromes parciais incluídas nos transtornos alimentares sem outra especificação (SMINK; VAN HOEKEN; HOEK, 2012; SWANSON et al., 2011).

Atualmente, especula-se sobre um aumento da incidência dos transtornos alimentares na população, aventando-se, inclusive, a vigência de uma epidemia. Estudos populacionais mostraram aumento de novos casos de anorexia até os anos 1970, época em que as taxas se estabilizaram. Em relação à bulimia, há uma tendência à queda na população em geral, a partir de meados da década de 90, embora a incidência em mulheres entre 10 e 19 anos permaneça estabilizada (SMINK; VAN HOEKEN; HOEK, 2012).

No Brasil, os estudos epidemiológicos se restringem a populações específicas (ALBERTON et al., 2013; ALVES et al., 2008; PETROSKI; PELEGRINI; GLANER, 2012; VALE; KERR; BOSI, 2011), não possibilitando uma inferência da prevalência desses quadros na população geral. De qualquer forma, a partir de nossa prática clínica em um serviço de referência para o Estado de Minas Gerais, podemos testemunhar a existência de uma demanda contínua e numerosa de tratamento nos diversos serviços públicos de saúde do Estado, proveniente, sobretudo, de pacientes jovens dos mais variados grupos socioeconômicos com sintomas alimentares.

Num país em que os corpos desnudos ganham proeminência não só pela tropicalidade do clima, mas também por razóes históricas e culturais, a imagem corporal assume, certamente, estatuto diferenciado (NOVAES, 2010). Entretanto, o corpo magro como ideal de beleza, como um atributo valorizado pela cultura, não é suficiente para explicar os processos anoréxicos e bulímicos contemporâneos. Esses quadros evidenciam, antes, uma desconexão entre o sujeito e o Outro (ou o discurso social), uma ruptura do vínculo que permitia a esse sujeito satisfazer-se na civilização, apesar de suas restrições (FREUD, 1930 [1929]). A satisfação pulsional obtida pela conquista ou posse de atributos 
socialmente valorizados é conhecida, na psicanálise, como satisfação fálica. Esta é diferente do que se verifica nas anorexias e bulimias em que os sujeitos estão fixados numa satisfação pulsional de natureza autoerótica, em ruptura com o relacional ou com o social.

Nos últimos anos, a mídia nacional tem abordado o tema, sobretudo após a morte de uma modelo brasileira por complicaçóes decorrentes de sintomas anoréxicos. Desde então, diversos projetos de lei voltados principalmente para a regulamentação de agências de modelos vêm sendo discutidos no Congresso Nacional. Entre essas propostas está a determinação de um Índice de Massa Corporal (IMC) $)^{4}$ mínimo para que as modelos possam ser veiculadas no mundo da moda (MACHADO, 2008).

Embora entendamos que essas medidas delineiam os contornos do desejável, limitando a valorização da obscenidade e do corpo tratado como objeto de consumo, é importante acentuar que elas não incidem sobre o empuxo que se anuncia no enlouquecimento da imagem, específico das anorexias e bulimias contemporâneas (EIDELBERG et al., 2004; 2009).

$\mathrm{Na}$ sociedade atual, observamos o império dos meios de comunicação de massa refletindo a economia do capitalismo e fazendo circular imagens instantâneas que passam a substituir as palavras. O ideal se desloca dos valores para as imagens, promovendo a frequência de identificaçoos rígidas e sem sentido, apoiadas na segurança de um gozo solitário (EIDELBERG et al., 2004). É a imagem pura que ganha proeminência nas anorexias e bulimias atuais, onde o que está em jogo é muito mais uma alteração da percepção da imagem do corpo, fenômeno conhecido na psicopatologia como dismorfofobia, do que uma alteração no comportamento alimentar.

\section{A alteração da imagem no espelho - pequeno percurso etiológico}

A experiência do espelho foi abordada de diversas maneiras por estudiosos, uma vez que se trata de um momento essencial no processo de maturação e desenvolvimento da criança. A novidade introduzida por Lacan (1949) foi a de elevar essa experiência ao status de um paradigma estrutural permanente da constituição da subjetividade humana.

Baseado em dados experimentais da psicologia comparada, Lacan elaborou, ao longo de seu ensino, o famoso estádio do espelho para se referir ao momento da 
constituição do eu, a partir da imagem do próprio corpo vista no espelho. Basta observarmos uma criança ainda imatura para o domínio motor e fisiológico, que constatamos a manifestação de júbilo que a imagem de seu corpo inteiro lhe causa. Nesse momento, ela olha para o adulto para encontrar no olhar do outro a confirmação do reflexo que vê. A partir daí, a criança se aliena nessa imagem "que marcará com sua estrutura rígida todo o seu desenvolvimento mental" (LACAN, 1949, p. 100), como primeiro momento da constituição do eu.

Lacan ressalta que a relação do sujeito consigo e com os outros será sempre atravessada por esse ponto a partir do qual o sujeito se vê. A confirmação do adulto através de seu olhar e a subjetivação pelo sujeito desse terceiro elemento (o ponto de vista) marcam a entrada do sujeito no simbólico, possibilitandolhe a representação de sua imagem corporal e propiciando a ligação do eu a situaçôes socialmente elaboradas. Esse processo descreve a formação do Ideal do eu como identificação simbólica que irá regular a relação do sujeito com sua imagem (LACAN, 1949).

A deformação da imagem corporal tão presente nas anorexias e bulimias atuais parece relacionar-se justamente com essa matriz simbólica, conhecida na psicanálise como Ideal do Eu. No mundo contemporâneo, historicamente marcado pelo declínio da capacidade do discurso de capturar a pulsão, ocorre um enfraquecimento do poder da instância simbólica, provocando, ao mesmo tempo, uma desorganização do campo imaginário. Sem o suporte de uma referência simbólica, sem o ponto de vista que Freud encontrou no Ideal do eu, a imagem vacila, deforma. Ela deixa de funcionar como um véu para um gozo que, assim, irrompe no espelho como carne, ou seja, como um excesso não simbolizado. É exatamente esse excesso que angustia as anoréxicas e bulímicas, que encontram no jejum e nas purgações uma forma de defesa (EIDELBERG et al., 2009).

Esse entendimento da questão nos permite repensar a efetividade das propostas que pretendem regular a suposta epidemia de anorexias e bulimias por meio de leis que visam controlar do peso das modelos e atenuar a segregação no mercado da moda, exigindo, por exemplo, que marcas famosas fabriquem roupas com tamanhos maiores. $\mathrm{Na}$ verdade, não se trata de tomar as anorexias e bulimias somente a partir de uma perspectiva empírico-sociológica, dando ênfase ao impacto do mundo da moda sobre os ideais de um corpo feminino 
esquálido. Talvez o ideal de magreza contribua para que, atualmente, tenhamos mulheres mais magras do que em outras épocas, mas não explica o fenômeno da dismorfofobia no mundo contemporâneo (EIDELBERG et al., 2004; 2009).

\section{As anorexias e bulimias na saúde pública}

Mas, afinal, devemos considerar as anorexias e bulimias um problema de saúde pública que justificaria discutir estratégias de intervenção no coletivo? Conforme discussão de Costa e Victoria (2006, p. 145), a definição do que é um "problema de saúde pública" deve considerar a carga de mortalidade, morbidade e sofrimento causados pela condição. Essa carga pode ser determinada pelo impacto no indivíduo (anos potenciais de vida perdidos, extensão da incapacidade, dor e desconforto, custo do tratamento individual e impacto familiar), assim como na sociedade (mortalidade, morbidade e custos do tratamento para a sociedade).

Apesar de os números indicarem que os transtornos alimentares são raros na população em geral, vale lembrar que eles são síndromes graves que afetam, sobretudo, adolescentes e adultos jovens do sexo feminino, causando prejuízos físicos, psíquicos e sociais que impactam tanto os pacientes quanto os serviços de saúde pública. A anorexia é a terceira doença crônica mais prevalente na adolescência e, entre todos os transtornos psiquiátricos, é a que apresenta as maiores taxas de mortalidade. Além disso, os pacientes com transtornos alimentares costumam apresentar uma qualidade de vida pior que a dos pacientes esquizofrênicos, paradigmas de gravidade na psiquiatria (TIRICO; STEFANO; BLAY, 2010; ARCELUS et al., 2011; SIMON; SCHMIDT; PILLING, 2005).

Embora Costa e Victoria (2006) questionem a caracterização de determinados agravos (como os distúrbios de sono e a esquizofrenia) no rol dos problemas de saúde pública, acreditamos que as altas taxas de morbidade, mortalidade e custos para a sociedade, indicados pela literatura médica e prática clínica, sejam suficientes para afirmarmos que as anorexias e bulimias constituem-se, sim, como problemas de saúde pública. Diante disso, esperamos que nosso trabalho contribua para o aperfeiçoamento das estratégias preventivas e da assistência a esse público. Mantendo as indicações iniciais da Saúde Coletiva, interessa-nos, igualmente, destacar o que esses sintomas revelam a respeito do laço social em nossos tempos e das condiçôes para que os sujeitos se incluam nele, encontrando formas de satisfação compatíveis com a vida em sociedade. 
Uma das questôes evidenciadas por esses quadros é a recusa, por parte dos pacientes, dos tratamentos padronizados. Eles nos lembram com isso que não há como uma prática na saúde coletiva preocupar-se com os problemas de grupos ou comunidades sem contemplar a clínica e a singularidade de cada caso.

\section{A experiência de um serviço na abordagem das anorexias e bulimias}

No Brasil, não existem políticas públicas de saúde que contemplem especificamente o atendimento de pacientes com transtornos alimentares. Estes são recebidos, comumente, por vários profissionais ao mesmo tempo (médicos clínicos, psiquiatras, psicólogos, nutricionistas), que, no entanto, trabalham isoladamente, adotando condutas sem nenhuma conexão e que não favorecem o tratamento dos casos ou só o fazem aleatoriamente.

Os transtornos alimentares, por envolverem tanto os problemas orgânicos quanto os psíquicos e relacionais, demandam uma abordagem em equipe, que facilite a contínua construção do caso e da conduta a ser mantida pelos diversos profissionais envolvidos. De fato, os serviços criados nas regiōes Sul e Sudeste do Brasil a partir dos anos 1980, em resposta a uma demanda já constituída, apostaram no formato da equipe interdisciplinar. Atualmente, temos o conhecimento de oito centros especializados em transtornos alimentares nessas regiōes: dois na cidade do Rio de Janeiro (GOTA-UFRJ, NUTRA-Santa Casa); quatro no Estado de São Paulo (AMBULIM-USP, PROATA-UNIFESP, PROATA/AMBULIM-USP e GRATA-USP-Ribeirão Preto); um em Porto Alegre (GEATA do CEPIA - ONG) e um em Belo Horizonte (NIAB-HC/ UFMG). Com exceção do GEATA, todos os serviços funcionam vinculados a centros universitários com proposta de atenção a pacientes, pesquisa e formação de profissionais (NUNES, 2006).

O NIAB-HC/UFMG (Núcleo de Investigação em Anorexia e Bulimia do Hospital das Clínicas da UFMG), cuja experiência nos ocupa aqui, nasceu como um grupo de estudos que congregava profissionais com diferentes formações, então envolvidos na atenção a demandas de saúde de adolescentes. O grupo reuniu novos profissionais interessados e, em 2004, formalizou-se como serviço especial, vinculado à Diretoria Clínica do HC-UFMG. Trata-se de um espaço dedicado à assistência a pacientes com sintomas anoréxicos e bulímicos de todas 
as idades, acolhendo, preferencialmente, pacientes encaminhados pela rede de saúde pública, em acordo com a Secretaria Municipal de Saúde de Belo Horizonte. $\mathrm{O}$ ambulatório mantido pela equipe do NIAB reúne profissionais médicos com formação em clínica, endocrinologia, nutrologia e psiquiatria; nutricionistas; psicanalistas e assistentes sociais. Seu quadro é, além disso, renovado a cada ano por profissionais em estágio, provenientes tanto de residências médicas, quanto de cursos de pós-graduação. Conta-se igualmente com a contribuição de profissionais interessados, em formação continuada.

Para construir a estratégia dos tratamentos, a equipe apoia-se no referencial teórico da psicanálise de orientação lacaniana. As metodologias primárias utilizadas são a escuta do sujeito e a construção do caso clínico (VIGANÒ, 1999), com as quais se visa obter o diagnóstico estrutural e encontrar a função do sintoma anoréxico/bulímico em cada caso. As discussões clínicas dos casos oferecem elementos que orientam a condução do tratamento por cada um dos profissionais envolvidos, possibilitando um trabalho interdisciplinar bem-sucedido.

A política do NIAB, norteada pelo sintoma, parte do pressuposto de que há algo nessa manifestação que funciona como uma solução singular para o sujeito. Como propõe Viganò (1999), a partir da construção do caso, tenta-se elucidar e transmitir o estatuto da solução sintomática de cada um, tornando-a compreensível para todos, independentemente de qualquer formação psicanalítica. Com essa metodologia, busca-se investigar a própria montagem do sintoma como resposta do sujeito aos impasses que ele encontra. Entendido dessa forma, o "sintoma-solução" pode ser, na medida do possível, respeitado no serviço, até que o sujeito encontre saídas menos devastadoras. Retoma-se, assim, o aforismo médico de que "existem doentes e não doenças". Esse entendimento promove um (re)posicionamento da equipe que modula o seu furor curandis a partir do princípio ético primum non nocere, ou seja, o princípio da não maleficência, de acordo com o qual a primeira preocupação para um médico será nunca prejudicar o seu paciente.

Tendo em vista as importantes repercussōes clínicas, nutricionais e psíquicas decorrentes dos transtornos alimentares, o NIAB tem pautado suas intervenções clínicas na ideia da redução de danos (CONTE, 2004) que, atualmente, é amplamente discutida para a abordagem de usuários de drogas.

Em contraste com o modelo centrado na doença, que vê o uso de drogas como uma patologia e a abstinência como única meta aceitável do tratamento, a redução 
de danos trabalha com uma ampla variedade de procedimentos que visam reduzir os prejuízos decorrentes do comportamento de risco. Trata-se de uma orientação menos centrada em um ideal de saúde e mais sensível às possibilidades de cada sujeito. A característica central dessa orientação é a flexibilidade no contrato com o paciente, valendo-se de propostas diversificadas e construídas com cada paciente e sua rede social. Dessa forma, pretende-se valorizar as singularidades e o tempo do sujeito, sem impor ideais preestabelecidos.

A estratégia de redução de danos pode ser utilizada no tratamento de várias patologias e, embora o assunto não tenha sido diretamente abordado na literatura médica referente aos transtornos alimentares, a essência da redução de danos tem sido discutida no NIAB, funcionando como importante argumento na definição do tratamento. Além das evidências do sucesso dessas estratégias em outros quadros, a possibilidade de uma articulação dessa proposta com o tratamento analítico contribui para que essa prática seja adotada no serviço.

Como alternativa às abordagens mais coercivas no tratamento dessas patologias, propõe-se, por exemplo, o "contrato de peso", a ser realizado com o paciente no início do tratamento. Esse tipo de contrato, proposto pela primeira vez por Hilde Bruch (1973), consiste em uma promessa mútua: o paciente se compromete a não perder mais peso e, em contrapartida, o médico jamais fará exigências alimentares ou de aumento do peso. Assim, embora o IMC possa ser usado como um valor de referência, tenta-se relativizá-lo no caso a caso. Essa abordagem está em consonância com a ideia de Lasègue (2000[1873]), um dos primeiros médicos a descrever a anorexia, de que quanto maior a insistência, maior a recusa do paciente. Além disso, desloca o entendimento dos transtornos alimentares, que deixam de ser considerados como meras inadequaçôes da ingesta alimentar e da percepção corporal que precisam ser retificados. Cria-se, ao mesmo tempo, um espaço para o trabalho de subjetivação das questôes ou acontecimentos que se encontram na gênese desses quadros.

Sempre atentos às possíveis complicaçôes clínicas e nutricionais das anorexias e bulimias, os médicos do NIAB atuam, inicialmente, no sentido de preservar a vida e minimizar as alterações clínicas decorrentes da desnutrição e dos comportamentos purgativos. A assistência apresenta um caráter predominantemente ambulatorial, com atendimentos semanais. Os casos mais graves, nos quais as condições clínicas e/ou psiquiátricas implicam risco eminente para o paciente, são encaminhados 
para tratamento em hospitais da rede de saúde de Belo Horizonte. Nesse tipo

de situação, existe a preocupação da equipe em manter o paciente internado o menor período de tempo possível, articulando o tratamento hospitalar com a proposta do tratamento ambulatorial.

Paralelamente à assistência que visa o corpo orgânico, ocorre um trabalho preliminar de toda a equipe na tentativa de resgatar a palavra e a história dos sujeitos em tratamento. Parte-se da ideia de que existe um sujeito nessa série repetitiva de fenômenos. Através da escuta cuidadosa das histórias, queixas, necessidades e demandas, busca-se resgatar a dignidade do sujeito e de seu sintoma, favorecer o estabelecimento de um laço com o serviço e com os profissionais diretamente envolvidos e obter elementos para a construção do caso. Na medida em que a eliminação dos sintomas alimentares não é colocada como o objetivo principal, os pacientes tendem a se sentir mais acolhidos e menos julgados, aderindo melhor ao tratamento.

Observa-se que, apesar de a equipe do NIAB estar orientada por uma mesma ética e por uma mesma política, ao buscar estratégias de tratamento a partir da construção dos casos, o serviço tende a se desdobrar em vários, podendo conviver com condutas díspares. A centralidade da construção do caso na organização do serviço visa garantir o respeito pela singularidade dos sujeitos na condução do tratamento. Algumas práticas da equipe, como a supervisão mensal realizada por um profissional externo convidado e a apresentação de paciente ${ }^{5}$ semestral, também realizada por profissional externo, contribuem para o aperfeiçoamento e valorização dessa tarefa central e cotidiana.

É ainda a construção do caso que permite à equipe sustentar a continuidade de tratamentos de longa duração ou daqueles em que uma recuperação não se faz tão evidente, do ponto de vista dos padrões médicos da normalidade. Através da construção do caso, conquista-se, com base na teoria psicanalítica, um saber a respeito do sujeito e não somente de sua condição patológica.

Levada ao limite, a ênfase na singularidade do caso e no sujeito questiona o próprio serviço, criado em torno da coletividade das anoréxicas e bulímicas. Se cada anorexia ou bulimia é única, porque agrupá-las num serviço? O motivo parece ser de atualidade: essa é a identidade que o diagnóstico médicopsiquiátrico oferece a esses sujeitos e que eles abraçam. Para dissolver, remover ou conservar esse diagnóstico, será preciso primeiro acolhê-lo como ele se apresenta 
para o indivíduo em nossa cultura científica. Pode-se dizer que a formação de coletividades desse tipo em nossa sociedade se impõe aos profissionais, inclusive àqueles que têm o sujeito como terreno privilegiado de sua intervenção terapêutica. Singularidade e coletividade se tensionam aqui, se questionam, no melhor dos casos. A política do NIAB está orientada pela tentativa de dissolução dessa identificação, a partir do momento em que outras identificações puderem estabelecer-se para o sujeito.

De outro modo, algo do social também se anuncia na constatação, por parte dos profissionais do NIAB, de algumas regularidades nas histórias dos pacientes. São bastante frequentes os casos em que os sintomas anoréxicos e bulímicos se associam a histórias de abandono na infância, a famílias ambíguas, obscenas, a abusos sexuais, a decepções amorosas, tudo isso vindo à tona, muito frequentemente, no momento da puberdade. Essas associações, embora significativas, não distinguem nitidamente os sujeitos acometidos pelos transtornos alimentares do conjunto de outros pacientes graves, com outros diagnósticos psiquiátricos, onde tais associações também são encontradas. De toda forma, os acontecimentos narrados pelos pacientes são uma mostra do estado da civilização atual, de seus pontos frágeis, aqueles pontos onde se instalou a via de uma recusa visceral do laço social.

A política do NIAB é pelo restabelecimento da possibilidade do laço e, de toda forma, pela busca, com os sujeitos em tratamento, de outros modos de expressão da recusa, menos colada no corpo e menos mortífera. Nesse sentido, o trabalho aí realizado reencontra o coletivo, permitindo, na medida de cada um, uma reintegração ou uma reacomodação.

\section{Anas, Bias, Marias e Joanas}

Dos casos relatados e discutidos nas reuniões clínicas, pela equipe do NIAB, escolhemos algumas passagens onde nos pareceu emergir a flexibilidade institucional exigida pela orientação clínica do NIAB.

Ana, uma senhora com um quadro anoréxico grave, teve, em uma de suas diversas internações, uma sonda nasogástrica instalada em seu corpo para alimentação enteral. Desde então, não aceita sua retirada. Ao contrário do que preconiza a literatura médica quanto às indicaçōes do uso da sonda nasogástrica, no caso de Ana, foi preciso entender que somente a utilização ininterrupta desse 
aparelho lhe permitiria manter sua mobilidade, suas relações familiares e evitar as inumeráveis internações. $\mathrm{O}$ entendimento da função dessa sonda na sustentação do corpo de Ana conteve as tentativas de sua remoção pela equipe, repercutindo com a estabilização do quadro clínico e psiquiátrico.

Para Lúcia, uma mulher emagrecida e decidida a manter a restrição alimentar, só foi possível retomar uma dieta razoável quando seu trabalho com o corpo pôde se deslocar para cuidados com a forma de se vestir. O reconhecimento do valor dessa báscula do sujeito permitiu orientar a condução do tratamento.

Maria, uma menina de 13 anos, só encontrou uma via para tratar sua rígida anorexia quando o serviço reconheceu e admitiu sua inteira dependência com relação à presença física da mãe. Nesse caso, o acolhimento conjunto de mãe e filha durante um longo período, questionava inclusive o próprio ponto de vista da psicanálise, que preconizaria, a princípio, o atendimento individualizado, entendendo que o tratamento de casos desse tipo passa por favorecer as possibilidades da separação entre mãe e filha.

Com a senhora Olívia, o serviço aprendeu a conviver com alguém que se mantém esquálida, entre a vida e a morte. Para ela, o aumento de poucas gramas precipita atuações graves direcionadas para a morte. Ser uma paciente "custosa" é uma solução que lhe permite introduzir um intervalo entre ela e um Outro que a invade e a prejudica. Esse caso é acompanhado pela equipe há cerca de oito anos e evidencia como o ideal de cura deve ser relativizado. Atualmente, a senhora Olívia está com 41 anos e, a despeito da magreza (IMC de $13 \mathrm{~kg} / \mathrm{m}^{2}$ ) e das queixas quanto à gordura, ela parou de abusar de laxantes e diuréticos. Encontra-se, na medida do possível, com o quadro clínico estabilizado. Já não fala mais em morrer e ressalta que (re)encontrou um lugar nesse serviço, onde ajusta semanalmente seu tratamento.

Já Bia, uma jovem insatisfeita com sua imagem corporal a ponto de abusar de laxantes e se isolar em seu quarto, só interrompe o uso desses medicamentos quando elabora sua forte decepção com o pai e encontra outro lugar no mundo, diferente do que tinha ao lado deste, restabelecendo seus vínculos sociais.

Joana, uma menina de nove anos, para de comer devido a vômitos incoercíveis. Ela só reencontra o prazer na alimentação e o rendimento escolar após uma intervenção que limitou sua exposição às questôes sexuais dos pais.

Em todos esses casos, houve um período preliminar de espera da equipe, marcado pelo acolhimento e cuidado do corpo, até que algo do inconsciente 
pudesse surgir ou até que o modo de satisfação pulsional pudesse se deslocar. $\mathrm{O}$ trabalho da escuta e da construção do caso permitiu manter a abertura necessária para que os sujeitos pudessem criar outras soluções mais compatíveis com a vida, sem a obrigatoriedade de uma readequação dos comportamentos a um ideal biomédico ou de saúde mental. Esse trabalho possibilita aos profissionais reconhecer as invenções de cada sujeiro, que se apresentam em movimentos nada padronizados, mas que viabilizam novamente uma vida em sociedade.

\section{Do singular ao coletivo}

Retomando o fio de nossos questionamentos a respeito do manejo das dimensões do coletivo e do singular no âmbito da experiência do NIAB, destacamos o que desse ponto de vista pudemos encontrar em nossa análise, até o momento.

Em primeiro lugar, parece relevante isolar o fato de que o serviço ambulatorial sustentado pelo NIAB caracteriza-se pela primazia concedida à singularidade dos casos, na orientação clínica, o que favorece o reconhecimento e a valorização das invenções de cada um. Tal política contrasta com as tentativas de padronização de procedimentos e de metas, calcados em ideais de produtividade e em parâmetros biomédicos preestabelecidos, bastante frequentes hoje nas instituições voltadas para o cuidado da saúde. Essa orientação clínica do NIAB combina-se com uma estrutura organizacional pouco regulamentada e bastante flexível, pronta a se curvar a definições alcançadas nas discussões da equipe de profissionais.

Outro aspecto importante é que o NIAB reúne uma população desagregada de sujeitos, que, no entanto, encontram na classificação psiquiátrica de anorexia e bulimia uma forma de inscrição para o que não anda bem. Cria-se com essa inscrição a possibilidade de endereçamento do apelo por cuidado, por parte de sujeitos e familiares, que, em geral, relutam em reconhecer a gravidade do que se apresenta. O trabalho do NIAB aposta, de sua parte, na possibilidade de um deslocamento ou da relativização dessa identificação, dependendo do caso.

Reconhecendo nos sintomas anoréxicos e bulímicos uma identificação que carrega a particularidade de uma satisfação pulsional autoerótica, fora das regulações oferecidas pela civilização, o trabalho clínico no NIAB visa à reconstrução da própria possibilidade de conexão do sujeito com os coletivos. $\mathrm{Ou}$ seja, visa-se a singularidade do caso para localizar o ponto em que se degradou a possibilidade, para um sujeito, de buscar satisfação no vínculo social. Nesse 
sentido, o serviço propõe-se a dar espaço e suporte às tentativas dos sujeitos de reconstruir suas conexões.

A política e o modo de funcionamento do NIAB oferecem-se como modelo alternativo para a abordagem de casos resistentes à racionalidade da gestão da saúde baseada na padronização das respostas e em ideais de bem-estar. Trata-se de uma clínica em que o que se encontra de saída é, muito frequentemente, a recusa do tratamento, a não adesão, a posição objetalizada e desconectada dos recursos sociais de um lado e, de outro, a angústia dos profissionais envolvidos no atendimento, qualquer que seja ele.

Levar em conta que no processo saúde, doença e intervenção existem o sujeito do inconsciente e a fixidez de uma satisfação pulsional, torna possível, de acordo com a experiência desse serviço, operar um deslocamento que favorece a participação ativa do sujeito na construção do seu modo singular de estar na vida e de relacionar-se, estabelecendo laços sociais afetivamente significativos.

Além disso, parece importante levar em conta que a própria delimitação e nomeação das coletividades em um momento histórico é um produto do embate dos saberes, do jogo das forças sociais e do mal-estar que habita determinada sociedade. A coletividade das anoréxicas e bulímicas é um bom exemplo disso: ela é ocasionada por um diagnóstico médico, que, no entanto, certamente isola um comportamento alimentar e social recorrente em nossos dias.

Se, por um lado, a nomeação dessas particularidades produz identificações e coletividades, permitindo pensar e intervir na dinâmica social, por outro, a pesquisa da singularidade visa tocar naquilo que separa, que distingue cada sujeito e que, por vezes, dificulta ou inviabiliza seu trânsito social. Assim, podese dizer que a clínica do singular reencontra o coletivo no que ela possibilita reinscrições do sujeito. ${ }^{6}$

\section{Referências}

ALBERTON, V.C. et al. Abnormal eating behaviors among medical students at a university in Southern Santa Catarina, Brazil. Rev. bras. educ. med. Rio de Janeiro, v. 37, n. 1, p. 1520, 2013.

ALVES, E. et al. Prevalence of symptoms of anorexia nervosa and dissatisfaction with body image among female adolescentes in Florianopolis, Santa Catarina State, Brazil. Cad. Saúde Pública. Rio de Janeiro, v. 24, n. 3, p. 503-512, 2008. 
ARCELUS, J. et al. Mortality rates in patients with anorexia nervosa and other eating disorders: a meta-analysis of 36 studies. Arch Gen Psychiatry, [S.1.], v. 68, n. 7, p. 724-731, 2011.

BRUCH, H. Eating disorders: obesity, anorexia nervosa, and the person within. New York: Basic Books, 1973.

CAMPOS, G.W. de S. Public health and collective health: field and core area for knowledge and practice. Ciênc. saúde coletiva. Rio de Janeiro, v. 5, n. 2, p. 219-230, 2000.

CONTE, M. Psicanálise e redução de danos: articulações possíveis. Revista da Associação Psicanalitica de Porto Alegre. Porto Alegre, n. 25, p. 23-33, 2004.

COSTA, J.S.D. da; VICTORA, C.G. O que é "um problema de saúde pública”? Rev. Bras. Epidemiol., São Paulo, v. 9, n. 1, p. 144-146, 2006.

EIDELBERG, A. et al. ¿Cómo tratan los psicoanalistas las anorexias y bulimias? Buenos Aires: Factoría Sur, 2004.

. Porciones de nada. La anorexia y la época. $1^{\text {a }}$ ed. Buenos Aires: Del Bucle, 2009.

FORBES, J. Inconsciente e responsabilidade: psicanálise do século XXI. São Paulo: Manole, 2012.

FREUD, S. Linhas de progresso na terapia psicanalítica. In: - Edição Standard

Brasileira das Obras Psicológicas Completas de Sigmund Freud. v.17, Rio de Janeiro: Imago, 1996 [1919 (1918)]. p. 173-181.

. O mal-estar na civilização. In: - Edição Standard Brasileira das Obras Psicológicas Completas de Sigmund Freud. v.21, Rio de Janeiro: Imago, 1996 [1930(1929)]. p. 73-153.

Análise terminável e interminável. In: Edição Standard Brasileira das Obras Psicológicas Completas de Sigmund Freud, v.23, Rio de Janeiro: Imago, 1996 [1937]. p. 231-274.

AMERICAN PSYCHIATRIC ASSOCIATION. DSM IV- TR: Manual diagnóstico e estatístico de transtornos mentais. 4a ed. rev. Porto Alegre: Artmed, 2002.

LACAN, J. A instância da letra no insconsciente ou a razão desde Freud. In:

Escritos. Rio de Janeiro: Jorge Zahar, 1998 [1957]. p. 496-533.

. O Seminário, livro 20: mais, ainda, 1972-1973. 3. ed. Rio de Janeiro: Jorge Zahar, 2008.

O estádio do espelho como formador da função do eu (1949). In:

Escritos. Rio de Janeiro: Jorge Zahar, 1998 [1949]. p. 96-103.

LASÈGUE, C. Sobre la anorexia histérica. Rev. Asoc. Esp. Neuropsiq., v. 20,n. 74, p. 271282, 2000 [1873].

MACHADO I.V. Transtornos alimentares em modelos adolescentes brasileiras: o culto ao corpo na pós-modernidade como causa de flexibilização das características inerentes aos 

GÊNERO, 8., Gênero, Violência e Poder, 2008, Florianópolis, SC. Anais (on-line), Florianópolis, UFSC, 2008. Disponível em: http://www.fazendogenero.ufsc.br/8/sts/ ST59/Isadora_Vier_Machado_59.pdf. Acesso em: 01 abril 2013.

MILLER, J-A. Rumo ao Pipol 4. Correio da EBP, n. 60, p. 7-14, 2009.

NOVAES, J.V. Com que corpo eu vou? Sociabilidade e usos do corpo nas mulheres das camadas altas e populares. Rio de Janeiro: PUC-RJ: Pallas, 2010.

NUNES, M.A. Transtornos alimentares e obesidade. Porto Alegre: Artmed, 2006.

ONOCKO-CAMPOS, R. Psicanálise e saúde coletiva: interfaces. São Paulo: Hucitec, 2012. PETROSKI, E.L.; PELEGRINI, A.; GLANER, M.F. Reasons and prevalence of body image dissatisfaction in adolescents. Ciênc. saúde coletiva, Rio de Janeiro v. 17, n. 4, p. 10711077, 2012.

SIMON, J.; SCHMIDT, U.; PILLING, S. The health service use and cost of eating disorders. Psychol Med., v. 35, n. 11, p. 1.543-1.551, 2005.

SMINK, F.R.E. ; VAN HOEKEN, D.; HOEK, H.W. Epidemiology of Eating Disorders: Incidence, Prevalence and Mortality Rates. Curr Psychiatry Rep , [S.1.], v. 14, n. 4, p.406414, 2012.

SWANSON, S. A. et al. Prevalence and correlates of eating disorders in adolescents: results from the national comorbidity survey replication adolescent supplement. Arch Gen Psychiatry, [S.1.], v. 68, n. 7, p. 714-723, 2011.

TIRICO, P. P.; STEFANO, S. C.; BLAY, S. L. Qualidade de vida e transtornos alimentares: uma revisão sistemática. Cad Saúde Pública, Rio de Janeiro, v. 26, n.3, p. 431-449, 2010.

VALE, A. M. O. do; KERR, L. R. S.; BOSI, M. L. M. Risk behaviors for eating disorders among female adolescents from different social strata in the Brazilian Northeastern. Ciênc. saúde coletiva, Rio de Janeiro, v. 16, n. 1, p. 121-132, 2011.

VIGANÒ, C. A construção do caso clínico em saúde mental. Revista Curinga, Belo Horizonte, n.13, p. 39-48, 1999.

\section{Notas}

${ }^{1}$ Optamos utilizar o termo "núcleo", referindo a Campos (2000), que cita a elaboração de Bourdieu sobre "campo" e "corpus" para contrapor a ideia de núcleo à de corpus (disciplina). Ao defender que a Saúde Coletiva seria um núcleo, ele reforça que, embora ela divida com o corpus a concepção de aglutinação de saberes e de práticas, não pretende uma institucionalização fechada que rompa com um campo mais amplo - nesse caso, a saúde -, o que possibilitaria uma relação mais flexível com este.

${ }^{2}$ Este artigo é originado de reflexões decorrentes de duas pesquisas, intituladas "Itinerários terapêuticos de pacientes com transtornos de anorexia e bulimia nervosas" e "Anorexias e Bulimias: contribuições da psicanálise para a Saúde Coletiva”, aprovadas, respectivamente, pelo COEP/UFMG (CAAE - 13907713.5.0000) e CEP/René Rachou/Fiocruz (CAAE - 23492213.1.0000). 
${ }^{3} \mathrm{O}$ Manual de Diagnóstico e Estatística dos Transtornos Mentais V(DSM V), recentemente publicado, alterou alguns dos critérios para o diagnóstico de anorexia e bulimia. Além disso, acrescentou o Transtorno de Compulsão Alimentar Periódica entre os transtornos alimentares. Neste artigo, usaremos o termo transtornos alimentares para nos referir às anorexias, bulimias e seus correspondentes incluídos entre os transtornos alimentares sem outra especificação.

${ }^{4} \mathrm{O}$ índice de massa corporal (IMC) é uma medida internacional calculada através da divisão do peso do indivíduo $(\mathrm{Kg})$ pelo quadrado de sua altura $\left(\mathrm{m}^{2}\right)$. Na medicina, de forma geral, para uma pessoa adulta, um IMC localizado entre 20 e $22 \mathrm{Kg} / \mathrm{m}^{2}$ indica quantidade ideal de gordura corporal.

${ }^{5}$ A apresentação de pacientes é uma prática tradicional na Psiquiatria Clássica, adotada por Lacan e que consiste numa entrevista pública com um paciente para posterior discussão, visando a reconduçôes do tratamento.

${ }^{6}$ A.C. Val e M.B. de Carvalho participaram da concepção, do projeto, da coleta e da análise dos dados, na redação final, revisão crítica relevante do conteúdo intelectual e aprovação da versão final. R.Onocko-Campos trabalhou na redação final do artigo, revisão crítica relevante do conteúdo intelectual e aprovação da versão final. 
Between the singular and the collective: the experience of a service in the approach to anorexia and bulimia

We investigate the handling of dimensions of the collective and the singular in the context of health services guided by psychoanalysis. A public health service where care is provided to patients diagnosed with bulimia and / or anorexia is described and analyzed. The psychoanalytic orientation is given by elaborating the clinical cases in an interdisciplinary team. Data were collected from service's files, observation and direct participation of the authors in clinical activities of the service. The privilege to the singularity in the clinic of this service as a treatment of the peculiarities of the collective is evidenced and discussed in terms of its implications for collective health.

> Key words: anorexia; bulimia; psychoanalysis; collective health. 